\title{
The moral and philosophical importance of abortion
}

\section{John Reynolds-Wright}

Fourth Year Medical Student, The Medical School, University of Sheffield, Sheffield, UK

\section{Correspondence to}

Mr John Reynolds-Wright, The Medical School, University of Sheffield, Beech Hill Road, Sheffield S10 2RX, UK: jjrw1989@gmail.com

Received 12 July 2012 Revised 17 October 2012 Accepted 31 October 2012
To cite: Reynolds-Wright J. Journal of Family Planning and Reproductive Health Care 2013, 39, 51-53.

\section{INTRODUCTION}

Access to safe abortion has been labelled as a fundamental human right by the International Women's Health Coalition, who stated that:

- A woman should have the choice to carry a pregnancy to term or not;

- Abortion services should be part of a comprehensive sexual health programme;

- Lack of funding and illegality do not reduce the number of abortions, they only serve to put the woman's health in danger. ${ }^{1}$

Despite this, abortion is illegal or difficult to access in many countries and has recently come under renewed attack in the Western world.

In the USA, certain states have introduced laws requiring women to listen to fetal heart beat monitors or to undergo a transvaginal ultrasound scan before being permitted to proceed with an abortion, with the thinly-veiled intent to discourage them.

Recently in the UK, MP Nadine Dorries proposed an amendment to abortion legislation that would have prevented abortion providers, such as Marie Stopes International and the British Pregnancy Advisory Service, from offering preabortion counselling to women on the basis that their advice was 'not independent'. They would instead be directed to 'Crisis Pregnancy Centres' for supposedly independent counselling. However, many of these centres are run and funded by religious groups with prominent antiabortion agendas. $^{2}$

The amendment was withdrawn due both to lack of support and to a national campaign against it. But the motives behind the amendment, and the more extreme pieces of legislation being passed in the USA, call for the arguments of legality, morality and access to be re-evaluated.

\section{TRADITIONAL ARGUMENTS}

\section{Against abortion}

A common argument against abortion is that it is equivalent to murder - specifically infanticide - and in this way it is immoral and unjustifiable.

One of the best known philosophical arguments to this effect is that of Don Marquis, who claimed that murder is illegal because it deprives the murdered person of their potential future. Consequently, abortion is murder as it deprives the fetus of its potential future, and therefore abortion is morally wrong and should not be allowed from the moment of conception. ${ }^{3}$ However, this does not take into consideration that the zygote formed at conception is a very different entity from that which will ultimately be born and go on to experience a future. ${ }^{4}$

Therefore, it could be reasoned that Marquis's argument rather endorses a policy of abortion up to the point of viability, as once a fetus has reached this stage it will be highly similar to a newborn child that can go on to experience a future.

\section{For abortion}

There are two main arguments in favour of abortion. First, that of Mary Anne Warren, who argued that it is a person, rather than simply a human being, that is entitled to rights, including the right to life. Abortion could therefore be deemed acceptable, as while a fetus is undeniably a human being, it is not a person. Warren goes further by suggesting that intelligent extraterrestrial beings could be regarded as persons and therefore deserving of rights, rather than rights being reserved only for humans, and goes on to list several criteria of personhood, including consciousness, reasoning, activity, communication and self-awareness. ${ }^{5}$ This argument is often objected to as it does not take into account that people who are temporarily comatose cannot fulfil her criteria of personhood and therefore could be killed with impunity as a result of her argument. Similarly, infants up to the age of 1 or 2 years can be incapable of fulfilling these criteria and so her argument could be used to justify infanticide. 
However, Warren has responded that from the point of birth a child does not need to biologically rely on its mother any longer as it can be cared for by anyone; thus if the mother did not want the child, killing it would not be her only option. ${ }^{5}$

The second argument is that of Judith Jarvis Thomson in 'A Defence of Abortion'. Her essay generates several 'thought experiments', the most discussed being that of 'The Violinist'. The world's top violinist falls ill and the Society of Music Lovers kidnaps you and hooks him up to you to make use of your kidneys for the next 9 months until he recovers. If you are parted any sooner, he will die. The essay then goes on to consider several assumptions and reasons that would make it permissible or impermissible to detach the violinist and leave him to die before the 9 months are over. ${ }^{6}$

The central principle of the argument is that even though the violinist has a right to life, that right does not supersede your right to choose whether or not to remain connected to the violinist for 9 months. Thomson considers the stance that in this instance you have been kidnapped by the Society for Music Lovers and have not chosen to participate, equating the whole thought experiment to pregnancy as a result of rape, and she accepts that this does not necessarily hold for a pregnancy resulting from consensual heterosexual intercourse. However, this argument relies on the assumption that pregnancy is a foreseeable consequence of heterosexual intercourse.

First, if a heterosexual couple engaging in sexual activity make use of one or more methods of contraception it can be said that while pregnancy is a foreseeable consequence, it is an unlikely one and the woman in this scenario does not morally or philosophically have a responsibility to give life to something that she took so much effort to avoid.

Second, a person may not necessarily associate the act of sexual intercourse with pregnancy; that is to say, when a person meets a member of the opposite sex to whom they are attracted, it is unlikely that their intention is to 'have a baby' with them, whereas they may intend to have sexual relations with them. This highlights a psychological separation between sex and 'making babies' that may lead to sexual behaviour that makes pregnancy more likely (not using contraception), as pregnancy is no longer a 'foreseeable' outcome. This is especially true for young people who are reaching sexual maturity, yet have not reached emotional maturity.

Related to this is the concept of 'normalised deviance', where an incorrect or unsafe action is carried out, but no negative consequence results, and so the incorrect or unsafe action becomes viewed as being correct and safe. This can be applied to having unprotected sex, but not getting pregnant. It can also apply to smoking a cigarette but not getting lung cancer. However, the greater the number of times the 'deviant' act is committed - be it unprotected sex or smoking cigarettes - the greater the likelihood that a negative consequence will result.

We do not condemn to death those who have contracted lung cancer due to smoking; rather, we offer them help and treatment. Similarly, it can be reasoned that a woman would be within her rights to terminate a pregnancy on the basis of not considering the outcomes of unprotected sexual intercourse, in other words, making a mistake.

\section{A NEW ARGUMENT}

Access to safe abortion is not only a human right; it is a measure of a society's development with regard to women.

Western society has a strong patriarchal basis, which has at least in part emanated from the influence of Christianity: the Bible and the teachings of the Church historically emphasise a woman's role as being the property of a man and to be subordinate to him. Gender equality only began to take steps forward in the UK as recently as 100 years ago and our society still retains many patriarchal features and influences, as can be seen in another bill proposed by Nadine Dorries, who wished to make abstinence education compulsory in the UK, but only for young girls. ${ }^{7}$

The ideology behind singling out young women as being responsible for saying no to sex is born out of the patriarchal notion of hegemonic masculinity: ${ }^{8}$ that it is a male's prerogative to be sexually driven and experienced and that it is natural for him to 'sow his wild oats', whereas a female should be modest and restrained lest she become pregnant, a condition that would have an irreversible effect on her life. Herein lies the importance of contraception and abortion.

First, contraception theoretically liberates women from the fear of falling pregnant, so allowing a different sexual culture to develop in which women are able to explore their sexuality, experiment and have multiple sexual partners in a way that had previously been the preserve of men. Second, and more importantly, abortion allows women to reverse what used to be an irreversible event in their lives. This comes into a greater degree of conflict with patriarchy and hegemonic masculinity than contraception does and is thus a more controversial issue.

Contraception can be viewed in a positive light by patriarchy and hegemonic masculinity as it can be seen to encourage women to engage in sex as they will not need to worry about the consequence, namely pregnancy. Abortion, however, is less acceptable as it is the act of removing and rejecting the sperm of a male. This goes against hegemonic masculinity and patriarchy, which emphasise the importance of virility and fertility of men. As such, a patriarchal society will be more inclined to oppose access to abortion as it is seen, by extension, to be an act of emasculation.

It is for this reason that access to abortion is such an important measure of progress. A society that permits 
abortion recognises that women are more important than the 'seed' of a male that they may be carrying.

\section{CONCLUSION}

As politicians and lobbying groups of varying backgrounds seek to restrain the rights of women in terms of access to abortion it must be remembered that: abortion is justifiable morally and philosophically; that abortion is a way for an individual woman to correct a mistake that she and her partner have made and avoid an otherwise unavoidable future; and that for women and society as a whole it is part of our further social evolution towards equality.

Funding None.

Competing interests None.

Provenance and peer review Not commissioned; externally peer reviewed.

\section{REFERENCES}

1 International Women's Health Coalition. Access to Safe Abortion is a Human Right. 2008. http://www.iwhc.org/storage/
iwhc/docUploads/Safe\%20Abortion_FINAL.pdf? documentID $=420$ [accessed 21 March 2012].

2 Quinn B, Curtis P, Strattton A. Anti-abortion bid in disarray as critics rally. The Guardian, 2 September 2011. http://www. guardian.co.uk/world/2011/sep/02/ anti-abortion-critics-nadine-dorries [accessed 21 March 2012].

3 Marquis D. Why abortion is immoral. J Philos 1989;86:183-202.

4 Stone J. Why potentiality matters. Can J Philos 1987; $17: 815-830$.

5 Warren MA. On the moral and legal status of abortion. Monist 1973;57:43-61.

6 Thomson J. A defense of abortion. Philos Public Aff 1971;1:47-66.

7 Shepherd J. MPs to debate sexual abstinence lessons bill. The Guardian, 20 January 2012. http://www.guardian.co.uk/ education/2012/jan/20/mps-debate-sexual-abstinence-bill [accessed 21 March 2012].

8 Hyde A, Drennan J, Howlett E, et al. Young men's vulnerability in constituting hegemonic masculinity in sexual relations. Am J Mens Health 2009;3:238-251. 